\title{
Distribution of Risk Factors in Parents and Siblings of Patients with Early Coronary Artery Disease
}

\author{
Antonio de Padua Mansur, André P. L. Mattar, Anderson L. Rolim, Fábio R. Yoshi, José F.G. Marin, \\ Luíz Antonio M. César, José Antonio F. Ramires
}

São Paulo, SP - Brazil

\begin{abstract}
Objective - Early coronary artery disease (CAD) is associated with risk factors $(R F)$. Offspring of parents with a RF have a greater prevalence of them. However, the distribution of RF in parents and siblings of patients with early $C A D$ is unknown.
\end{abstract}

Methods - The study comprised the parents and siblings of 42 patients with early CAD ( $\leq 45$ years), 29 males. Their mean age was $39.5 \pm 3.7$ years. The following major $R F$ were analyzed: smoking ( $\geq 5$ cigarretes/day), hypercholesterolemia (total cholesterol $\geq 200 \mathrm{mg} / \mathrm{dL}$ ), hypertension (diastolic blood pressure $\geq 90 \mathrm{mmHg}$ ), and diabetes (glycemia $\geq 126 \mathrm{mg} / \mathrm{dL}$ ).

Results - Of a total of $102 \mathrm{RF}, 4,3,2$, and 1 were observed in, respectively, 5, 15, 15, and 7 patients with early $C A D$, the most prevalent being smoking (86\%) and hypercholesterolemia (83\%). Diabetes was observed in 15 (36\%) and hypertension in $16(38 \%)$ patients. Smoking was more prevalent in the fathers (76\%) and hypercholesterolemia in the mothers (30\%). In 183 siblings, $131 \mathrm{RF}$ were observed (1 patient with the disease had a mean of 4.7 siblings). The prevalences of smoking, hypertension, hypercholesterolemia, and diabetes in the siblings were, respectively, $32 \%, 18 \%, 14 \%$, and $9 \%$. The incidence of RF was as follows: 72 (39\%) siblings had 1 RF, 25 (14\%) siblings had $2 R F$, and $3(2 \%)$ siblings had $3 R F$. In parents and their offspring, smoking was moderately correlated $(r=0.43 ; P=0.02)$ with $C A D$.

Conclusion - Smoking habit of parents is passed on to offspring, and, in association with hypercholesterolemia, it was the major cause of early CAD in offspring. High prevalence of smoking in offspring shows the potential responsibility of parents in the incidence of the disease in offspring.

Key words: coronary artery disease, risk factors, familial history, smoking

Instituto do Coração do Hospital das Clínicas - FMUSP

Mailing address: Antonio de Padua Mansur - InCor - Av. Dr. Enéas C. Aguiar, 44 05403-090 - São Paulo, SP, Brazil - E-mail: corantonio@incor.usp.br English version by Stela Maris C. e Gandour
Coronary artery disease is the major cause of death in the Brazilian population ${ }^{1}$ and is directly related to the number and intensity of risk factors ${ }^{2}$, which may be generically divided into unchangeable (age and sex) and changeable. The major changeable risk factors are obesity, sedentary lifestyle, systemic arterial hypertension, smoking, dyslipidemia, and diabetes. Smoking and sedentary lifestyle are basically behavioral, and the remaining risk factors are associated with genetic and environmental components. Studies in different populations have shown the greater importance of environmental and behavioral components in the genesis of the atherosclerotic process ${ }^{3}$. A classical example is the greater prevalence of the disease in individuals migrating from a more favorable environment to one with a more atherogenic profile ${ }^{4}$. Likewise, some studies ${ }^{5,6}$ have shown the importance of the microenvironment, in particular the family, where genetic influences and lifestyle are equally important. Offspring of parents with systemic arterial hypertension or with dyslipidemia have a greater incidence of diseases whose phenotypes are influenced by the familiar lifestyle. The result of this interaction is responsible for atherosclerotic disease, which normally affects males after the 6 th decade and females almost 1 decade later ${ }^{7}$. In younger patients with coronary artery disease, a greater participation of the genetic component has been discussed. Despite the existing controversies, a familiar analysis may directly or indirectly facilitate the detection and quantification of which component, genetic or environmental, has the greatest impact on early atherosclerotic disease, and, consequently, on its future control. Therefore, the major objective of this study was to analyze the prevalence of risk factors in families of patients with early systemic arterial disease, and to detect the importance of parents in the vertical transmission of these risk factors.

\section{Methods}

This study prospectively analyzed the distribution of the major risk factors of parents and siblings of 42 conse- 
cutive patients of the outpatient care clinics of the Group of Chronic Coronary Heart Diseases of the Instituto do Coração (InCor) of the Hospital das Clínicas of the Medical School of the University of São Paulo diagnosed with early coronary artery disease ( $\leq 45$ years) from August to November 1999. Their ages ranged from 30 to 45 years (mean \pm $\mathrm{SD}=39.5 \pm 3.7$ years). Twenty-nine $(69 \%)$ patients were males and $13(31 \%)$ were females. The diagnosis of coronary artery disease was angiographic and defined as obstructive atherosclerotic lesions $\geq 50 \%$ in at least 1 subepicardial coronary artery. The major risk factors studied were as follows: smoking ( $\geq 5$ cigarretes/day), systemic arterial hypertension (diastolic pressure $\geq 90 \mathrm{mmHg}$ ) ${ }^{8}$, and diabetes (glycemia $\geq$ $126 \mathrm{mg} / \mathrm{dL})^{9}$. Hypercholesterolemia was diagnosed as total cholesterol levels $\geq 200 \mathrm{mg} / \mathrm{dL}$ or LDL-cholesterol levels $\geq 130 \mathrm{mg} / \mathrm{dL}^{10}$.

The calculation of the sample size $(\mathrm{N}=15$ families $)$ for the study was based on proportion-type variables with a significance level of $\alpha=0.05$, a statistical power of $1-\beta=$ $80 \%$, and transmission of at least $50 \%$ of the risk factors. The statistical analysis used the chi-square test for categorical variables, the Student $t$ test for analysis of the fractions comprising the lipid profile, and the Pearson test for the correlations between the risk factors of parents and offspring. The statistical significance level of $\mathrm{P}<0.05$ was adopted.

\section{Results}

A total of 102 risk factors were observed in the patients with early coronary artery disease, and their distribution of $4,3,2$, and 1 was respectively detected in $5,15,15$, and 7 patients. The most prevalent risk factors were smoking $(86 \%)$ and hypercholesterolemia ( $83 \%$ ) followed by diabetes (38\%) and systemic arterial hypertension (36\%). Smoking was more prevalent in the father $(48 \%)$ and hypertension in the mother (24\%). Table I shows the distribution of the general characteristics and lipid profile.

At least 1 risk factor was observed in $50 \%$ of the mothers and in $55 \%$ of the fathers (NS). In 183 siblings, 131 risk factors were observed as follows: 54 (41\%) siblings had 1 risk factor, $25(19 \%)$ had 2 risk factors, and $9(7 \%)$ siblings had 3 risk factors. The relation of 1 patient with coronary artery disease had a mean of 4.7 siblings and 1.3 risk factors.

Only 2 siblings also had coronary artery disease. The prevalence of smoking, hypertension, hypercholesterolemia, and diabetes in the siblings was, respectively, $31 \%$, $17 \%, 13 \%$, and $8 \%$. A moderate correlation $(\mathrm{r}=0.43 ; \mathrm{P}=0.02)$ between the smoking habit of parents and offspring and the disease was observed. No correlation was detected between the risk factors of mothers and offspring or their siblings and the disease, or fathers and offspring also with the disease. Among ill offspring, 35 (83\%), 6(14\%), and 1 (2\%) patients had, respectively, single-, double-, or triple vessel disease, depending on the number of impaired coronary arteries. The lipid profile of the population was similar in the groups, except for HDL-cholesterol in mothers and offspring with coronary artery disease $(\mathrm{P}=0.008)$. All

\begin{tabular}{|c|c|c|c|c|}
\hline \multicolumn{5}{|c|}{$\begin{array}{c}\text { Table I - Clinical characteristics and distribution of risk factors in } \\
\text { parents and offspring with coronary artery disease (CAD) } \\
\text { and their siblings }\end{array}$} \\
\hline & Fathers & Mother & $\begin{array}{l}\text { Offspring } \\
\text { with } C A D\end{array}$ & Siblings \\
\hline & $(\mathrm{N}=40)$ & $(\mathrm{N}=40)$ & $(\mathrm{N}=42)$ & $(\mathrm{N}=183)$ \\
\hline Mean age (years) & $68.4 \pm 9.5$ & $65.2 \pm 7.3$ & $39.5 \pm 3.7$ & $38.4 \pm 4.6$ \\
\hline Sex (male/female) & $40 / 0$ & $0 / 40$ & $29 / 13$ & $87 / 96$ \\
\hline Smoking & $19(76 \%)$ & $8(20 \%)$ & $36(86 \%)$ & $58(32 \%)$ \\
\hline Hypercholesterolemia & $5(12 \%)$ & $12(30 \%)$ & $35(83 \%)$ & $32(18 \%)$ \\
\hline Systemic arterial hypertensi & n $4(10 \%)$ & $7(17 \%)$ & $16(38 \%)$ & $25(14 \%)$ \\
\hline Diabetes & $4(10 \%)$ & $7(17 \%)$ & $15(36 \%)$ & $16(9 \%)$ \\
\hline Risk factors (total) & 32 & 34 & 102 & 131 \\
\hline 0 & $18(45 \%)$ & $20(50 \%)$ & 0 & $83(45 \%)$ \\
\hline 1 & $17(42 \%)$ & $11(27 \%)$ & $7(16 \%)$ & $72(39 \%)$ \\
\hline 2 & $4(10 \%)$ & $7(17 \%)$ & $15(36 \%)$ & $25(14 \%)$ \\
\hline 3 & $1(2 \%)$ & $3(7 \%)$ & $15(36 \%)$ & $3(2 \%)$ \\
\hline 4 & $1(2 \%)$ & 0 & $5(12 \%)$ & 0 \\
\hline Triglycerides (mg/dL) & $229 \pm 86$ & $230 \pm 75$ & $220 \pm 46$ & $232 \pm 86$ \\
\hline Total cholesterol (mg/dL) & $245 \pm 59$ & $236 \pm 62$ & $232 \pm 49$ & $229 \pm 29$ \\
\hline HDL-cholesterol $(\mathrm{mg} / \mathrm{dL})$ & $43 \pm 9$ & $46 \pm 8$ & $38 \pm 17 * *$ & $41 \pm 6$ \\
\hline LDL-cholesterol (mg/dL) & $152 \pm 38$ & $149 \pm 32$ & $140 \pm 35$ & $138 \pm 26$ \\
\hline \multicolumn{5}{|c|}{$\begin{array}{l}* \mathrm{P}<0.0001 \text { for the prevalence of familial antecedents among offspring with } \\
\mathrm{CAD} \text { and their siblings; } * * \mathrm{P}=0.008 \text { for HDL levels between mothers and } \\
\text { offspring with CAD }\end{array}$} \\
\hline
\end{tabular}

patients with the disease were taking lipid-lowering drugs (statins). Two patients used fibrates concomitantly.

\section{Discussion}

This study stresses 2 important points: 1) the great majority of patients with early coronary artery disease has an important changeable risk factor; and 2) the vertical transmission of risk factors from parents to offspring was more environmental or related to lifestyle than to the genetic component. Some studies have shown that offspring or siblings of patients with coronary artery disease may have conditions ranging from phenotypic correspondence of a certain risk factor to a greater mortality due to cardiovascular diseases ${ }^{11}$, suggesting the important participation of the genetic component passed on by parents ${ }^{12,13}$. However, genetic studies in animals and human beings have shown difficulties in identifying the genes directly related to coronary artery disease ${ }^{14,15}$. Some of these genes have been more constantly associated with coronary artery disease, either in its acute (acute coronary syndromes) or in its chronic form in case-control or meta-analysis studies $^{16-18}$. However, these associations disappear in longitudinal studies ${ }^{19-21}$, suggesting the greater importance of the environmental component. Inadequate diet and lifestyle potentiate a risk factor with some degree of genetic influence (systemic arterial hypertension, dyslipidemia and diabetes) and favor other mainly behavioral risk factors, such as smoking and a sedentary lifestyle. Lifestyle and diet are, therefore, the major determinants of the phenotypic expression of major changeable risk factors (systemic arterial hypertension, dyslipidemia and diabetes). A recent stu$\mathrm{dy}{ }^{22}$ has emphasized that smoking and diet were the major 
risk factors responsible for postprandial hyperlipemia, which is known to be a condition associated with the atherosclerotic process. An improvement in these determinants is associated with better control of these risk factors and a reduction in the incidence of the coronary artery disease ${ }^{23}$. Recommendations, although not systematic, to change lifestyle and life habits result in improvement in the control of risk factors ${ }^{24}$. Therefore, families with individuals at high risk for developing coronary artery disease may benefit from this educational process, which will cause an improvement in all risk factors. This process applied to our population could reduce the incidence of the disease in young individuals, because our data showed that $86 \%$ of our study population were smokers and $83 \%$ had some degree of dyslipidemia, smoking being considered the most important factor for coronary artery disease. A recent study ${ }^{25}$ showed an al- most 6-time greater risk for coronary artery disease in female smokers. As smoking is a behavioral risk factor, quitting smoking offers the best cost-benefit ratio for reducing the disease. Medications, in addition to being expensive, are usually associated with side effects; however, most of the time, they are not required. In developing countries, where the social cost is usually high due to other diseases, a reduction in smoking through an educational process is the major approach for reducing cardiovascular diseases. This educational process will influence parents to quit smoking, and, consequently, reduce smoking in offspring.

This study reveals the important participation of the parental habit of smoking in offspring. Therefore, it is the responsibility of parents to control the smoking habit as early as possible, because the incidence of smoking among young people has been increasing.

\section{References}

1. MansurAP, Favarato D, Souza MFM, et al. Tendência da mortalidade por doenças circulatórias no Brasil de 1979 a 1996. Arq Bras Cardiol 2001;76:497-503.

2. Kuulasmaa K, Tunstall-Pedoe H, Dobson A, et al. Estimation of contribution of changes in classic risk factors to trends in coronary-event rates across the WHO MONICA Project populations. Lancet 2000;355:675-87.

3. Kromhout D, Keys A, Aravanis C, et al. Food consumption patterns in the $1960 \mathrm{~s}$ in seven countries. Am J Clin Nutr 1989;49:889-94.

4. Kagan A, Harris BR, Winkelstein W Jr, et al. Epidemiologic studies of coronary heart disease and stroke in Japanese men living in Japan, Hawaii and California: demographic, physical, dietary and biochemical characteristics. J Chronic Dis 1974;27:345-64.

5. BrandãoAP, BrandãoAA, Araujo EM, Oliveira RC. Familial aggregation of arterial blood pressure and possible genetic influence. Hypertension 1992;19(Suppl II):II214-7.

6. Brenn T. Adult family members and their resemblance of coronary heart disease risk factors: the cardiovascular disease study in finnmark. Eur J Epidemiol 1997;13:623-30.

7. Lerner DJ, Kannel WB. Patterns of coronary heart disease morbidity and mortality in the sexes: a 26-year follow-up of the Framingham population. Am Heart J 1986;111:383-90.

8. III Consenso Brasileiro de Hipertensão. Rev Bras Cardiol 1999;3:96-100.

9. American Diabetes Association: clinical practice recommendations 1999. Diabetes Care 1999;22 (Suppl 1):S1-114.

10. Consenso Brasileiro Sobre Dislipidemias: detecção, avaliação e tratamento. Arq Bras Cardiol 1996;67:113-128.

11. YoussefAA, Srinivasan SR, Elkasabany A, Chen W, Berenson GS. Trends of lipoprotein variables from childhood to adulthood in offspring of parents with coronary heart disease: the Bogalusa Heart Study. Metabolism 2001;50:1441-6.

12. Hunt SC, Williams RR, Barlow GK. A comparison of positive family history definitions for defining risk of future disease. J Chronic Dis 1986;39:809-21.

13. Marenberg ME, Risch N, Berkman LF, Floderus B, de Faire U. Genetic susceptibility to death from coronary heart disease in a study of twins. N Engl J Med 1994;330:1041-6.

14. Scheuner MT. Genetic predisposition to coronary artery disease. Curr Opin Cardiol 2001;16:251-60.
15. Niccoli G, Iacoviello L, Cianflone D, Crea F. Coronary risk factors: new perspectives. Int J Epidemiol 2001;30(Suppl 1):S41-7.

16. Mansur AP, Annicchi-Bizzacchi J, Favarato D, Avakian SD, César LAM, Ramires JAF. Angiotensin-converting enzyme and apolipoprotein B polymorphisms in coronary artery disease. Am J Cardiol 2000; 85:1089-93.

17. Samani NJ, Thompson JR, O'Toole L, et al.A meta-analysis of the association of the deletion allele of the angiotensin-converting enzyme gene with myocardial infarction. Circulation 1996;94:708-12.

18. Wilson PW, Schaefer EJ, Larson MG, Ordovas JM. Apolipoprotein E alleles and risk of coronary disease. A meta-analysis. Arterioscler Thromb Vasc Biol 1996; $16: 1250-5$.

19. Lindpaintner K, Pfeffer MA. Kreutz R, et al. A prospective evaluation of an angiotensin-converting-enzyme gene polymorphism and the risk of ischemic heart disease. N Engl J Med 1995;332:706-11.

20. Marshall HW, Morrison LC, Wu LL, et al. Apolipoprotein polymorphisms fail to define risk of coronary artery disease. Results of a prospective, angiographically controlled study. Circulation 1995;89:567-77.

21. Samani NJ, Martin DS, Brack M, et al. Apolipoprotein E polymorphism does not predict risk of restenosis after coronary angioplasty. Atherosclerosis 1996; 125:209-16.

22. Sharrett AR, Heiss G, Chambless LE, et al. Metabolic and lifestyle determinants of postprandial lipemia differ from those of fasting triglycerides: the Atherosclerosis Risk in Communities (ARIC) study. Arterioscler Thromb Vasc Biol 2001;21:275-81.

23. Kromhout D, Menotti A, Kesteloot H, Sans S. Prevention of coronary heart disease by diet and lifestyle: evidence from prospective cross-cultural, cohort, and intervention studies. Circulation 2002;105:893-8.

24. Steptoe A, Doherty S, Rink E, Kerry S, Kendrick T, Hilton S. Behavioural counselling in general practice for the promotion of healthy behaviour among adults at increased risk of coronary heart disease: randomised trial. Br Med J 1999;319:943-7.

25. Stampfer MJ, Hu FB, Manson JE, Rimm EB, Willett WC. Primary prevention of coronary heart disease in women through diet and lifestyle. N Engl J Med 2000;343:16-22 